\title{
Discussion of "Atmospheric deposition as an important nitrogen load to a typical agro-ecosystem in the Huang-Huai-Hai Plain" by Huang et al. (2016)
}

\author{
Yuepeng Pan ${ }^{\mathrm{a}, *}$, Wen Xu ${ }^{\mathrm{b}}$, Gregory R. Wentworth ${ }^{\mathrm{c}}$, Shili Tian ${ }^{\mathrm{a}}$ \\ a State Key Laboratory of Atmospheric Boundary Layer Physics and Atmospheric Chemistry (LAPC), Institute of Atmospheric Physics, Chinese Academy of \\ Sciences, Beijing 100029, China \\ b State Key Laboratory of Urban and Regional Ecology, Research Center for Eco-Environmental Sciences, Chinese Academy of Sciences, Beijing 100085, China \\ ${ }^{\mathrm{c}}$ Department of Chemistry, University of Toronto, 80 St. George Street, Toronto M5S 3H6, Canada
}

\section{A R T I C L E I N F O}

\section{Article history:}

Received 13 May 2016

Accepted 3 January 2017

Available online 5 January 2017

\section{Keywords:}

Nitrogen deposition

Ammonia

Wet deposition

Dry deposition

North China Plain

\begin{abstract}
A B S T R A C T
In a recent publication of Atmospheric Environment, Huang et al. (2016) reported nitrogen (N) deposition estimates using the water surrogate surface method. This method may be suitable to evaluate the atmospheric $\mathrm{N}$ input to a body of water, wetland or paddy fields rather than dry crop land without sustained waterlogged conditions. Such a method may also result in the potential underestimation of both dry and wet $\mathrm{N}$ deposition due to the release of ammonia $\left(\mathrm{NH}_{3}\right)$ from water evaporation and/or $\mathrm{N}$ loss from biological activities, and hence bias the relative contribution of dry deposition to total deposition. Besides the uncertainties regarding the magnitude and pathways of $\mathrm{N}$ deposition, the statement by Huang et al. (2016) that "nitrate was the dominant species in N deposition even in cropland" is also questionable. We suggest that reduced species dominate the $\mathrm{N}$ deposition in Huang-Huai-Hai Plain (i.e., North China Plain) even in urban and industrial regions due to the abundance of $\mathrm{NH}_{3}$.
\end{abstract}

๑) 2017 Elsevier Ltd. All rights reserved.
In a recent publication in the journal Atmospheric Environment, Huang et al. (2016) reported nitrogen $(\mathrm{N})$ deposition based on water as a surrogate surface in the Huang-Huai-Hai Plain (HP), which is also known as the North China Plain (NCP). The method they used may be suitable to evaluate the atmospheric $\mathrm{N}$ input to a body of water, wetland or paddy fields, but it may be unsuitable for dry land without sustained waterlogged conditions. In addition, there are several topics that need to be discussed regarding the magnitude, pathways and species of $\mathrm{N}$ deposition in the NCP.

\section{Magnitude of nitrogen deposition}

In the study by Huang et al. (2016), the authors reported that annual total $\mathrm{N}$ deposition ranged from 23.8 to $40.3 \mathrm{~kg} \mathrm{~N} \mathrm{ha}^{-1}$ (2008-2012) and averaged $31.8 \mathrm{~kg} \mathrm{~N} \mathrm{ha}^{-1}$. Their sampling site in the HP was surrounded by intensive agricultural areas and close to Quzhou (QZ) and Yucheng (YC) sites in NCP (Fig. 1), with same

DOI of original article: http://dx.doi.org/10.1016/j.atmosenv.2016.01.015.

* Corresponding author.

E-mail address: panyuepeng@mail.iap.ac.cn (Y. Pan). cropping system (i.e. a winter wheat-summer maize rotation). However, their measurement is substantially lower than previous estimations at QZ and YC (approximately $60 \mathrm{~kg} \mathrm{~N} \mathrm{ha}^{-1}$ ) with a similar level of the annual application rate of $\mathrm{N}$ fertilizers (500-700 $\mathrm{kg} \mathrm{N} \mathrm{ha}^{-1} \mathrm{yr}^{-1}$ ) and similar meteorological conditions (e.g. annual air temperature and precipitation) (Pan et al., 2012; Xu et al., 2015). In general, $\mathrm{N}$ deposition measured in agricultural areas tends to be higher than that observed in urban and rural areas, due to the fact that ammonia emissions in fertilized farmland are large (Pan et al., 2012).

The underestimation by Huang et al. (2016) is likely due to uncertainty of the method using distilled water to sample wet and dry $\mathrm{N}$ deposition. First, a water surface cannot act as the sink for gaseous $\mathrm{NO}_{\mathrm{x}}$ as its solubility is very low, and thus the water surface method would undoubtedly underestimate dry deposited $\mathrm{NO}_{\mathrm{x}}$ gas. Second, during their sampling interval (3-5 days), the collected water-soluble gases (e.g. $\mathrm{HNO}_{3}$ and $\mathrm{NH}_{3}$ ) may escape from water evaporation when air temperature is high, in particular during summer at cropland sites. This is evident from a recent publication concerning the pervasive release of $\mathrm{NH}_{3}$ from evaporating dew (Wentworth et al., 2016). Third, $\mathrm{N}$ losses via biological nitrification and denitrification may also occur since no measure was 


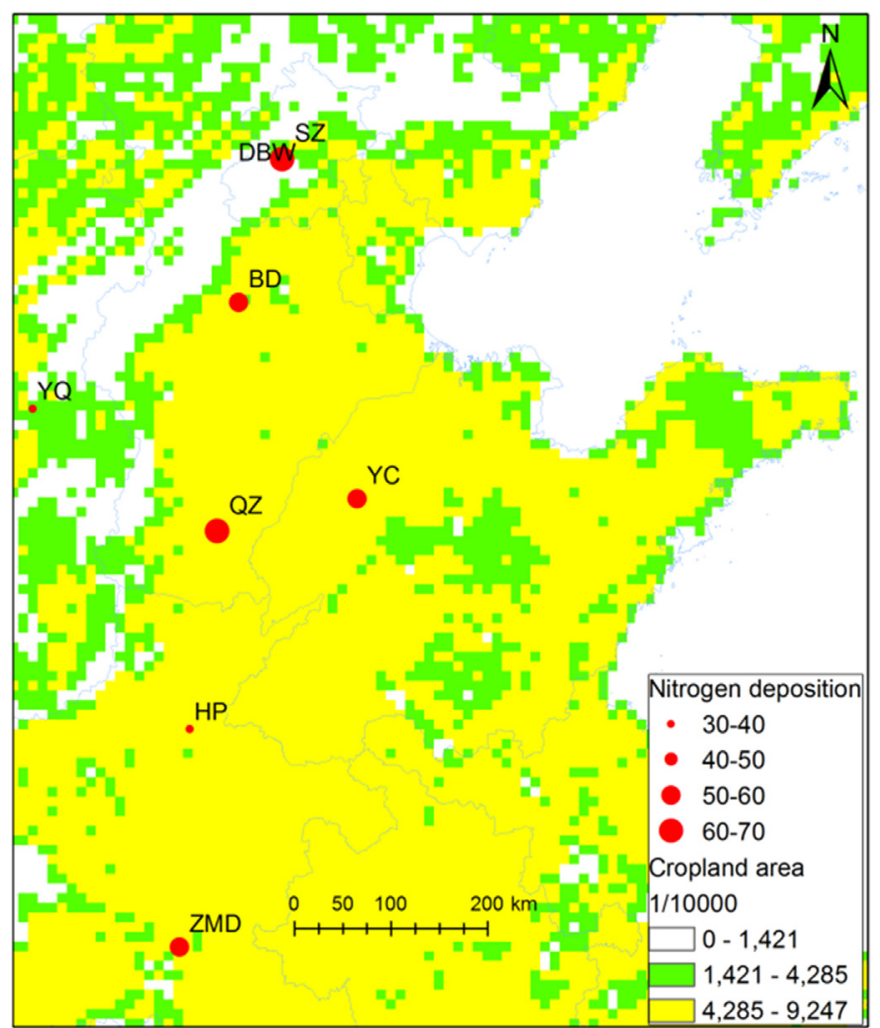

Fig. 1. Nitrogen deposition value observed at HP site by Huang et al. (2016) and other sites in NCP (Pan et al., 2012; Xu et al., 2015), with the gridded areas denoting cropland area $(1 / 10000)$.

implemented to inhibit biological activity (e.g. adding sodium azide). Therefore, the results obtained with the water surrogate surface method may reflect the remaining portion of the total inorganic $\mathrm{N}$ deposition (excluding $\mathrm{NO}_{\mathrm{x}}$ deposition) after $\mathrm{NH}_{3}$ volatilization and $\mathrm{N}$ loss.

\section{Pathways of nitrogen deposition}

Due to the aforementioned underestimation, estimates of the relative contribution of dry deposition to total deposition of $\mathrm{N}$ have been biased. Huang et al. (2016) suggested that "the average contribution of dry deposition to total values of $65 \%$, which was parallel to the results reported in the neighboring area (Shen et al., 2009)". However, Shen et al. (2009) only reported dry deposition and not wet deposition. It is therefore difficult to deduce the contribution of dry deposition to the total deposition (wet plus dry) based on Shen et al. (2009), although it is widely accepted that dry deposition is equally as important as wet deposition (Dentener et al., 2006).

We agree that there are significant uncertainties in dry deposition estimates, but wet deposition is more easily measured by analyzing $\mathrm{N}$ species in precipitation. Based on four-year (2008-2012) observations at the study site, however, Huang et al. (2016) reported the annual average wet inorganic $\mathrm{N}$ deposition as 11.2 (range of $6.4-16.1$ ) $\mathrm{kg} \mathrm{N} \mathrm{ha}^{-1}$, which is only half of that measured with wet-only method in agricultural areas of Shandong (24.8 $\mathrm{kg} \mathrm{N} \mathrm{ha}^{-1} \mathrm{yr}^{-1}$ ) and Hebei (22.1 $\mathrm{kg} \mathrm{N} \mathrm{ha}^{-1} \mathrm{yr}^{-1}$ ) during 2008-2010 (Pan et al., 2012). The wet estimates by Huang et al. (2016) are also substantially lower than measured bulk deposition of 24.8 (range of $21.6-27.4$ ) $\mathrm{kg} \mathrm{N} \mathrm{ha}^{-1} \mathrm{yr}^{-1}$ at five cropland sites in the NCP during 2010-2014 (Xu et al., 2015).
Besides, the annual mean dry inorganic $\mathrm{N}$ deposition of 13.5 (range of 10.6-20.0) $\mathrm{kg} \mathrm{N}^{-1} \mathrm{yr}^{-1}$ reported by Huang et al. (2016) is significantly lower than previous estimates using the inferential method (Pan et al., 2012; Xu et al., 2015). Together, we argue that the inorganic $\mathrm{N}$ deposition results by Huang et al. (2016) are underestimated due to the uncertainties of the method they used to estimate dry and wet deposition. The higher deposition results in this region are reasonable given that the NCP is one of the greatest emitters of $\mathrm{N}$-containing air pollutants (e.g. $\mathrm{NH}_{3}$ and $\mathrm{NO}_{\mathrm{x}}$ ) nationally and globally. This is evident from a series of publications based on the atmospheric deposition observation network in NCP, including urban, suburban, industrial, agricultural and rural sites (Pan and Wang, 2014; Pan et al., 2012, 2013).

\section{Species of nitrogen deposition}

Huang et al. (2016) reported the average molar ratio of ammonium to nitrate in dry and wet inorganic $\mathrm{N}$ as 3.1 (range of 2.1-4.9) and 2.3 (range of $1.9-3.4$ ), both of which are significantly higher than that observed at the aforementioned five cropland sites (about averaged 1.3) (Xu et al., 2015). Despite the difference in the ratio, both studies indicate the dominance of reduced species in the $\mathrm{N}$ deposition. Regarding the species of $\mathrm{N}$ deposition, we thus cannot agree with Huang et al. (2016) that "even with the impact of $\mathrm{N}$ fertilization in the agriculture-dominated sites of north and east China, nitrate was the dominant species in N deposition". Although several studies were cited by Huang et al. (2016), only one supports their viewpoint, i.e., Yang et al. (2010). In general, the dominant contribution of reduced $\mathrm{N}$ in wet and dry deposition is widely found in the NCP and other agricultural regions (Pan et al., 2012; Xu et al., 2015). N deposition composition data were consistent with China's national $\mathrm{NH}_{3}$ and $\mathrm{NO}_{\mathrm{x}}$ emission trends and similar decreasing ratios of $\mathrm{NH}_{3}-\mathrm{N}$ : $\mathrm{NO}_{\mathrm{x}}-\mathrm{N}$ from 1980 to 2010, suggesting the increased importance of oxidized $\mathrm{N}$ emissions and deposition in China (Liu et al., 2016). To date, however, even in urban and industrial sites, reduced $\mathrm{N}$ is still the major contributor ( 70\%) to total inorganic N deposition in the NCP (Pan et al., 2012).

In addition, the water-based surrogate method developed by Huang et al. (2016) cannot mimic the dynamics of atmospheric $\mathrm{N}$ deposition on plant canopies. For example, $\mathrm{NH}_{3}$ is subject to a bidirectional flux, which requires additional evaluation in the context of the stomatal compensation point in the NCP (Pan et al., 2012). Apart from these clarifications, we agree with Huang et al. (2016) that we need to provide more data collected by different methods and techniques as references to obtain reliable results due to the lack of standard protocols for $\mathrm{N}$ deposition sampling in such intensively managed agroecosystems. In summary, $\mathrm{NH}_{3}$ likely contributes a dominant portion of the total N deposition in the NCP and should be quantified with reliable methods in future.

\section{Conclusion}

In the original paper, Huang et al. (2016) reported $\mathrm{N}$ deposition estimates using the water surrogate surface method. This method may be suitable to evaluate the atmospheric $\mathrm{N}$ input to a body of water, wetland or paddy fields rather than dry crop land without sustained waterlogged conditions. Such a method may also result in the potential underestimation of both dry and wet $\mathrm{N}$ deposition due to the release of $\mathrm{NH}_{3}$ from water evaporation and/or $\mathrm{N}$ loss from biological activities, and hence bias the relative contribution of dry deposition to total deposition. Besides the uncertainties regarding the magnitude and pathways of $\mathrm{N}$ deposition, the statement by Huang et al. (2016) that "nitrate was the dominant species in N deposition even in cropland" is also questionable. We suggest that reduced species dominate the $\mathrm{N}$ deposition in North 
China Plain even in urban and industrial regions due to the abundance of $\mathrm{NH}_{3}$.

\section{Acknowledgments}

This work was supported by the National Basic Research Program of China (No.: 2016YFD0800302, 2012CB417101 \& 2012CB417106) and the National Natural Science Foundation of China (No.: 41405144 \& 41321064).

\section{References}

Dentener, F., Drevet, J., Lamarque, J., Bey, I., Eickhout, B., Fiore, A.M. Hauglustaine, D., Horowitz, L., Krol, M., Kulshrestha, U., 2006. Nitrogen and sulfur deposition on regional and global scales: a multimodel evaluation. Glob. Biogeochem. cycles 20 (4). http://dx.doi.org/10.1029/2005GB002672.

Huang, P., Zhang, J., Ma, D., Wen, Z., Wu, S., Garland, G., Pereira, E.I.P., Zhu, A., Xin, X Zhang, C., 2016. Atmospheric deposition as an important nitrogen load to typical agro-ecosystem in the Huang-Huai-Hai Plain. 2. Seasonal and interannual variations and their implications (2008-2012). Atmos. Environ. 129, 1-8. http://dx.doi.org/10.1016/j.atmosenv.2016.01.015.

Liu, X., Xu, W., Du, E., Pan, Y., Goulding, K., 2016. Reduced nitrogen dominated nitrogen deposition in the United States, but its contribution to nitrogen deposition in China decreased. Proc. Natl. Acad. Sci. 113 (26), E3590-E3591. http:// dx.doi.org/10.1073/pnas.1607507113.

Pan, Y.P., Wang, Y.S., 2014. Atmospheric wet and dry deposition of trace elements at ten sites in Northern China. Atmos. Chem. Phys. Discuss. 14 (14), 20647-20676. http://dx.doi.org/10.5194/acpd-14-20647-2014

Pan, Y.P., Wang, Y.S., Tang, G.Q., Wu, D., 2012. Wet and dry deposition of atmospheric nitrogen at ten sites in Northern China. Atmos. Chem. Phys. 12 (14), 6515-6535. http://dx.doi.org/10.5194/acp-12-6515-2012.

Pan, Y.P., Wang, Y.S., Tang, G.Q., Wu, D., 2013. Spatial distribution and temporal variations of atmospheric sulfur deposition in Northern China: insights into the potential acidification risks. Atmos. Chem. Phys. 13 (3), 1675-1688. http:// dx.doi.org/10.5194/acp-13-1675-2013.

Shen, J.L., Tang, A.H., Liu, X.J., Fangmeier, A., Goulding, K.T.W., Zhang, F.S., 2009. High concentrations and dry deposition of reactive nitrogen species at two sites in the North China Plain. Environ. Pollut. 157 (11), 3106-3113. http://dx.doi.org/ 10.1016/j.envpol.2009.05.016.

Wentworth, G.R., Murphy, J.G., Benedict, K.B., Bangs, E.J., Collett Jr., J.L., 2016. The role of dew as a nighttime reservoir and morning source for atmospheric ammonia. Atmos. Chem. Phys. 16 (11), 7435-7449. http://dx.doi.org/10.5194/ acp-16-7435-2016.

Xu, W., Luo, X.S., Pan, Y.P., Zhang, L., Tang, A.H., Shen, J.L., Zhang, Y., Li, K.H., Wu, Q.H., Yang, D.W., Zhang, Y.Y., Xue, J., Li, W.Q., Li, Q.Q., Tang, L., Lu, S.H., Liang, T., Tong, Y.A., Liu, P., Zhang, Q., Xiong, Z.Q., Shi, X.J., Wu, L.H., Shi, W.Q., Tian, K., Zhong, X.H., Shi, K., Tang, Q.Y., Zhang, L.J., Huang, J.L., He, C.E., Kuang, F.H. Zhu, B., Liu, H., Jin, X., Xin, Y.J., Shi, X.K., Du, E.Z., Dore, A.J., Tang, S., Collett Jr., J.L., Goulding, K., Sun, Y.X., Ren, J., Zhang, F.S., Liu, X.J., 2015. Quantifying atmospheric nitrogen deposition through a nationwide monitoring network across China. Atmos. Chem. Phys. 15 (21), 12345-12360. http://dx.doi.org/10.5194/acp15-12345-2015.

Yang, R., Hayashi, K., Zhu, B., Li, F., Yan, X., 2010. Atmospheric $\mathrm{NH}_{3}$ and $\mathrm{NO}_{2}$ concentration and nitrogen deposition in an agricultural catchment of Eastern China. Sci. Total Environ. 408 (20), 4624-4632. http://dx.doi.org/10.1016/ j.scitotenv.2010.06.006. 